\title{
Литий-алюминиевые слюды копей Мокруша и Министерская, Мурзинские самоцветные копи, Средний Урал
}

\author{
Гвозденко Т.А., ${ }^{1,2}$ Бакшеев И.А. ${ }^{1}$, Герасимова Е.И. ${ }^{2}$ \\ ${ }^{1}$ Московский государственный университет им. М.В. Ломоносова, Москва \\ ${ }^{2}$ Государственный геологический музей им. В.И. Вернадского РАН, Москва, t.gvozdenko@sgm.ru
}

Аннотация: Мурзинские самоцветные копи, насчитывающие более 250 пегматитовых тел с редкометальной минерализацией и ювелирными камнями (турмалин, топаз, берилл и др.) входят во всемирно известную Самоцветную полосу Урала. Минералы группы слюд являются важнейшими индикаторами физикохимических условий образования пегматитов и, как правило, содержат значительное количество редких элементов. В работе приведены результаты исследования литий-алюминиевых слюд из копей Мокруша и Министерская. По данным микрозондового анализа, в слюдах из копи Мокруша впервые установлен цезиевый аналог трилитионита в виде прожилков и многочисленных вростков в лепидолите. Результаты ИК-спектроскопии позволяют отличить литиевые слюды от других минералов группы слюд. В целом полученные аналитические данные свидетельствуют о схожести литий-алюминиевых слюд изученных копей.

Ключевые слова: литий-алюминиевые слюды, редкометальные пегматиты, самоцветные пегматиты, Мурзинский гранитный массив, копь Мокруша, копь Министерская.

\section{Lithium-aluminium micas from the Mokrusha and Ministerskaya mines, Murzinka gemstone district, Central Urals}

\author{
Gvozdenko T.A. ${ }^{1,2}$, Baksheev I.A. ${ }^{1}$, Gerasimova E.I. ${ }^{2}$ \\ ${ }^{1}$ Moscow State University, Moscow \\ 2Vernadsky State Geological Museum of RAS, Moscow,t.gvozdenko@sgm.ru
}

\begin{abstract}
The Murzinka gemstone district with more than 250 pegmatite bodies with rare-element mineralization and gemstones (tourmaline, topaz, beryl, etc.) is a part of the world famous Urals Gemstone Belt. Minerals of the mica group are one of the most important indicators of the physical-chemical conditions of pegmatite formation and usually contain a significant amount of rare elements. Here are the results of the study of lithium-aluminum micas from the Mokrusha and Ministerskaya mines. The cesium analogue of trilithionite in mica from the Mokrusha mine was established for the first time (according to the electron microprobe analysis). The results of IR spectroscopy make it possible to distinguish Li-mica from the others. In general, the analytical data confirm the similarity of the lithiumaluminum micas from both mines.
\end{abstract}

Key word: lithium-aluminium mica, rare-element pegmatite, gem-bearing pegmatite, Murzinka granite pluton, Mokrusha mine, Ministerskaya mine.

Мурзинские самоцветные копи входят в знаменитую на весь мир Самоцветную полосу Урала. Копи расположены в одноименном гранитном массиве примерно в 100 км к северу от Екатеринбурга. Пегматиты с редкометальной минерализацией и самоцветами приурочены к гранитным жилам, прорывающим протерозойские метаморфиты (Ферштатер и др., 2018).

В пределах Мурзинского гранитного массива насчитывается более 250 редкометальных и самоцветных пегматитов. Общее количество описанных минеральных видов - более 160 (Канонеров и др., 2000).

Копь Мокруша - одна из самых известных и хорошо изученных копей Самоцветной полосы Урала, расположена в 8 км севернее села Мурзинка на Среднем Урале. Первые упоминания о добыче минералов в этом районе относятся к концу XVIII века. В гранитных пегматитах установлено 79 минералов, в том числе минералы группы слюд: флогопит, аннит, сидерофиллит, мусковит, масутомилит и Li-Al слюды (Попов и др., 1999).

Копь Министерская также была открыта в конце XVIII века (1787 г.), но менее изучена. Пегматитовая жила располагается в нескольких километрах южнее деревни Сарапулка. Копь получила известность благодаря находкам малинового турмалина (Канонеров и др., 2000). 
Таблица 1. Химический состав слюд из копей Мокруша и Министерская (мас. \%).

Table 1. Composition of mica from the Mokrusha and Ministerskaya mines (wt. \%).

\begin{tabular}{|c|c|c|c|c|c|c|c|c|c|c|}
\hline № образца & 1 & 2 & 3 & 4 & 5 & 6 & 7 & 8 & 9 & 10 \\
\hline Тип & Л & Л & ЛМ & Л & ЦЛ & ЛМ & Л & ЛМ & Л & Л \\
\hline $\mathrm{SiO}_{2}$ & 53.19 & 49.93 & 44.63 & 50.57 & 46.50 & 43.58 & 58.72 & 51.43 & 55.55 & 50.70 \\
\hline $\mathrm{TiO}_{2}$ & нпо & нпо & нпо & нпо & нпо & 0.15 & нпо & нпо & 0.33 & нпо \\
\hline $\mathrm{Al}_{2} \mathrm{O}_{3}$ & 22.81 & 22.38 & 32.14 & 22.67 & 12.87 & 35.99 & 16.62 & 28.41 & 19.26 & 27.02 \\
\hline $\mathrm{FeO}$ & 0.40 & 5.12 & 0.02 & 2.00 & 0.79 & 0.82 & нпо & 0.25 & 0.06 & 0.01 \\
\hline $\mathrm{MnO}$ & 0.15 & 1.48 & 0.02 & 2.89 & 0.29 & 0.61 & 0.16 & 0.39 & 1.13 & 0.11 \\
\hline $\mathrm{MgO}$ & 0.25 & нпо & нпо & нпо & 0.04 & 0.01 & нпо & 0.04 & нпо & нпо \\
\hline $\mathrm{CaO}$ & 0.11 & нпо & 0.04 & 0.05 & 0.06 & 0.04 & нпо & 0.05 & 0.04 & 0.04 \\
\hline $\mathrm{Na}_{2} \mathrm{O}$ & 0.18 & 0.27 & 0.09 & 0.33 & нпо & 0.41 & 0.08 & 0.06 & 0.12 & 0.26 \\
\hline $\mathrm{K}_{2} \mathrm{O}$ & 9.91 & 9.97 & 11.23 & 10.16 & 0.67 & 10.47 & 10.72 & 7.61 & 10.11 & 10.72 \\
\hline $\mathrm{Rb}_{2} \mathrm{O}$ & 2.27 & нпо & 0.35 & 1.39 & 0.76 & нпо & 1.12 & 0.49 & 2.41 & 1.12 \\
\hline $\mathrm{Cs}_{2} \mathrm{O}$ & 0.37 & 0.68 & 0.16 & 0.31 & 24.58 & нпо & 0.56 & 0.43 & 0.57 & 0.96 \\
\hline $\mathrm{Li}_{2} \mathrm{O}_{\text {pac. }}$ & 5.71 & 4.77 & 0.12 & 4.96 & 3.78 & 0.72 & 6.46 & 0.63 & 6.40 & 4.99 \\
\hline $\mathrm{F}$ & 6.77 & 8.50 & 0.42 & 9.11 & 6.29 & 1.57 & 8.96 & 1.43 & 8.45 & 7.83 \\
\hline $\mathrm{H}_{2} \mathrm{O}_{\text {pac. }}$ & 1.33 & 0.37 & 3.99 & 0.11 & 0.57 & 3.64 & 0.29 & 3.68 & 0.55 & 0.84 \\
\hline $\mathrm{O}=\mathrm{F}$ & -2.85 & -3.58 & -0.18 & -3.84 & -2.65 & -0.66 & -3.77 & -0.60 & -3.56 & -3.30 \\
\hline Сумма & 100.60 & 98.99 & 93.03 & 100.71 & 94.55 & 97.34 & 101.12 & 94.30 & 101.09 & 101.30 \\
\hline
\end{tabular}

Формульные коэффициенты, рассчитанные на 22 отрицательные единицы заряда

\begin{tabular}{|l|c|c|c|c|c|c|c|c|c|c|}
\hline $\mathrm{Si}$ & 3.515 & 3.404 & 3.192 & 3.420 & 3.926 & 2.981 & 3.818 & 3.532 & 3.659 & 3.339 \\
\hline $\mathrm{Al}^{\mathrm{IV}}$ & 0.485 & 0.596 & 0.808 & 0.580 & 0.074 & 1.019 & 0.182 & 0.468 & 0.341 & 0.661 \\
\hline$\Sigma_{\text {тетр. }}$ & 4.000 & 4.000 & 4.000 & 4.000 & 4.000 & 4.000 & 4.000 & 4.000 & 4.000 & 4.000 \\
\hline $\mathrm{Al}^{\mathrm{VI}}$ & 1.292 & 1.202 & 1.901 & 1.226 & 1.206 & 1.883 & 1.092 & 1.832 & 1.154 & 1.437 \\
\hline $\mathrm{Ti}$ & - & - & - & - & - & 0.008 & - & - & 0.016 & - \\
\hline $\mathrm{Fe}^{2+}$ & 0.022 & 0.292 & 0.001 & 0.113 & 0.056 & 0.047 & - & 0.014 & 0.003 & 0.001 \\
\hline $\mathrm{Mn}^{2+}$ & 0.008 & 0.085 & 0.001 & 0.166 & - & 0.035 & 0.009 & 0.023 & 0.063 & 0.006 \\
\hline $\mathrm{Mg}^{2+}$ & 0.025 & - & - & - & 0.005 & 0.001 & - & 0.004 & - & - \\
\hline $\mathrm{Li}_{\text {рас. }}$ & 1.519 & 1.308 & 0.036 & 1.348 & 1.284 & 0.197 & 1.912 & 0.175 & 1.694 & 1.323 \\
\hline$\Sigma_{\text {окт. }}$ & 2.865 & 2.887 & 1.939 & 2.853 & 2.551 & 2.171 & 3.013 & 2.047 & 2.930 & 2.766 \\
\hline $\mathrm{K}$ & 0.835 & 0.867 & 1.025 & 0.876 & 0.072 & 0.914 & 0.852 & 0.667 & 0.849 & 0.901 \\
\hline $\mathrm{Ca}$ & 0.008 & - & 0.003 & 0.004 & 0.005 & 0.003 & - & 0.004 & 0.003 & 0.003 \\
\hline $\mathrm{Na}$ & 0.023 & 0.036 & 0.012 & 0.043 & - & 0.054 & 0.014 & 0.008 & 0.015 & 0.033 \\
\hline $\mathrm{Rb}$ & 0.096 & - & 0.016 & 0.060 & 0.041 & - & 0.089 & 0.022 & 0.102 & 0.047 \\
\hline $\mathrm{Cs}$ & 0.010 & 0.020 & 0.005 & 0.009 & 0.885 & - & 0.021 & 0.013 & 0.016 & 0.027 \\
\hline$\Sigma_{\text {м/сл }}$ & 0.973 & 0.922 & 1.061 & 0.993 & 1.004 & 0.971 & 0.975 & 0.713 & 0.986 & 1.011 \\
\hline $\mathrm{F}$ & 1.415 & 1.832 & 0.095 & 1.948 & 1.679 & 0.340 & 1.750 & 0.311 & 1.760 & 1.631 \\
\hline $\mathrm{OH}$ & 0.585 & 0.168 & 1.905 & 0.052 & 0.321 & 1.660 & 0.250 & 1.689 & 0.240 & 0.369 \\
\hline
\end{tabular}

Примечание: Копь Мокруша: 1 - №60 (1); 2 - №57; 3 - №55 (5); 4 - №51.1; 5 - №60 (2); копь Министерская: 6 - №37.1 (1); 7 - №36(1); 8 - №32 (2); 9 - №27 (1); 10 - №33 (1); Л - лепидолит; ЛМ - Lі-мусковит; ЦЛ - Cs-лепидолит; нпо - содержание элемента ниже предела обнаружения; Li рассчитан по Tischendorf, 1997; Н 2 О рассчитана по стехиометрии.

В данной работе приводятся результаты исследования литий-алюминиевых слюд из копей Мокруша и Министерская, а также их сравнительная характеристика. Литий-алюминиевые слюды 


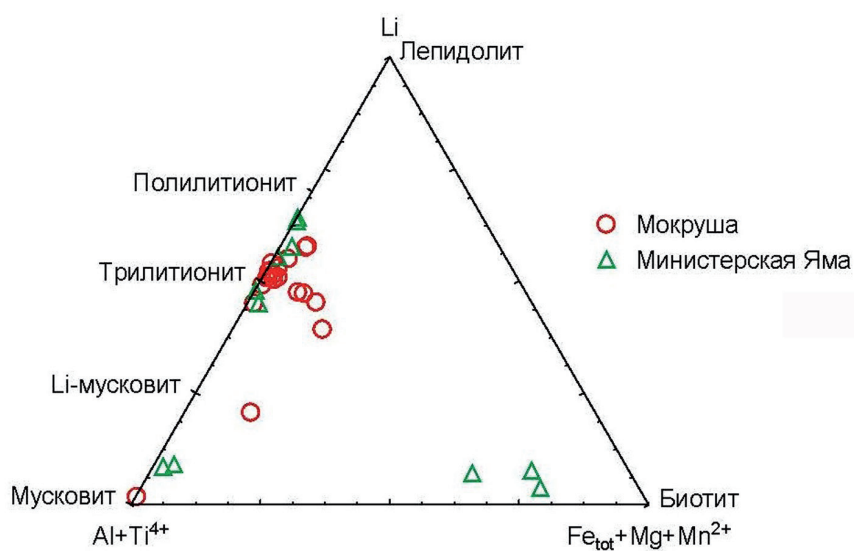

Рис.1 Треугольная диаграмма состава октаэдрических катионов в Li-Al слюдах копей Мокруша и Министерская.

Fig.1. Triangular diagram of the octahedral cations composition for Li-Al micas from the Mokrusha and Ministerskaya mines.

гранитных пегматитов обеих копей представлены 2 генерациями: ранней и поздней. Ранние слюды образуют пластины, мелкочешуйчатые агрегаты и крупные зональные кристаллы светло-серого, светло-розового и светло-фиолетового цвета до 5.5 см в поперечнике. Поздние слюды представлены мелкозернистой светлой слюдой в виде присыпок на калиевом полевом шпате.

По данным микрозондового анализа, в образцах гранитных пегматитов из обеих копей установлены: литиевый мусковит, трилитионит и полилитионит. Представительные химические анализы слюд из копей Мокруша и Министерская приведены в таблице 1. Большая часть химических составов соответствует трилитиониту (рис. 1). В трех образцах из копи Мокруша установлен Cs-трилитионит (11.38-24.58 мас. \% $\mathrm{Cs}_{2} \mathrm{O}$ ) в виде прожилков и вростков неправильной формы в трилитионите (рис. 2).
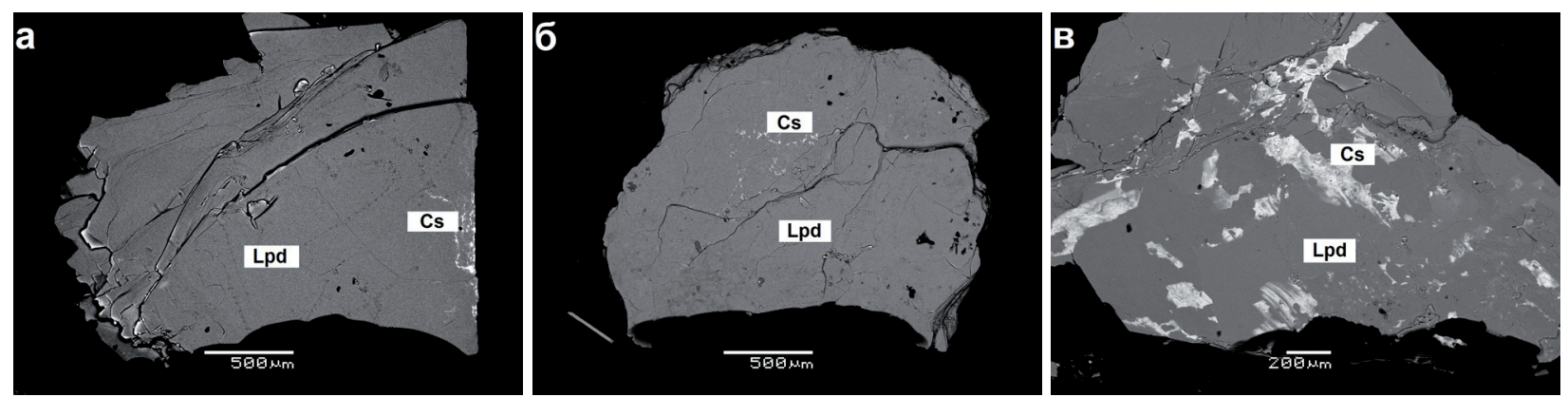

Рис. 2. Вростки Сs-трилитионита в слюдах из копи Мокруша (№56.1 - a, №58 - б, № 60 - в). Фото в отраженных электронах.

Fig. 2. BSE images of Cs-trilithionite embeddings in micas from the Mokrusha mine (№56.1 - a, №58 - б, №60 - в).

Большая часть изученных слюд относится к триоктаэдрическим. Трилитионит и полилитионит копи Министерская отличается повышенным содержанием $\mathrm{SiO}_{2}$ (до 59.29 мас. \%), $\mathrm{Al}_{2} \mathrm{O}_{3}$ (до 27.02 мас. \%) и $\mathrm{Li}_{2} \mathrm{O}_{\text {рас }}$ (до 7.48 мас. \%). Содержание $\mathrm{Rb}_{2} \mathrm{O}$ и $\mathrm{Cs}_{2} \mathrm{O}$ в обеих копях примерно совпадает.

Диоктаэдрические слюды встречаются реже, представлены Li-мусковитом и их химический состав из обеих копей схож, мас. \%: 43.58-53.02 $\mathrm{SiO}_{2}, 28.41-35.99 \mathrm{Al}_{2} \mathrm{O}_{3}, 7.61-11.23 \mathrm{~K}_{2} \mathrm{O}$, 0.35-0.72 $\mathrm{Rb}_{2} \mathrm{O}, 0.26-2.99 \mathrm{Cs}_{2} \mathrm{O}, 0.42-2.73 \mathrm{~F}$ и 0.12-1.49 $\mathrm{Li}_{2} \mathrm{O}_{\text {рас }}$.

Методом ИК-спектроскопии в большинстве изученных слюд установлены следующие поло-

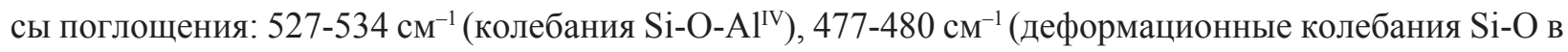
тетраэдрах), 443-448 см$^{-1}$ (колебания Si-O-Li). В ИК-спектрах Li-мусковита в аналогичной области выявлены только две полосы поглощения: 475-480 $\mathrm{cm}^{-1}$ и $535 \mathrm{~cm}^{-1}$ (рис. 3). В ближней ИК области спектров диоктаэдрических слюд присутствуют колебания группы $\mathrm{OH}^{-}\left(3625-3644 \mathrm{~cm}^{-1}\right)$. В триоктаэдрических слюдах полосы поглощения, характерные для $\mathrm{OH}^{-}$, слабо проявлены, либо отсутствуют, что отвечает замещению $\mathrm{OH}^{-}$на F (Павлишин, 1975; Beran, 2002). 
Рис. 3. ИК-спектры слюд: 1 - биотит, №47(1), копь Министерская; 2 - Li-мусковит, №37(1), копь Министерская; 3 - Li-мусковит, №31.1, копь Министерская; 4 - трилитионит, № 56, копь Мокруша; 5 - полилитионит, № 54, копь Мокруша; 6 - полилитионит, № 48, копь Министерская.

Fig. 3. FTIR spectra of mica: 1 - biotite, №47(1), Minesterskaya mine; 2 - Li-muscovite, №37(1), Minesterskaya mine; 3 - Li-muscovite, №31.1, Minesterskaya mine; 4 - trilithionite, № 56, Mokrusha mine; 5 -polylithionite, №54, Mokrusha mine; 6 - polylithionite, № 48, Minesterskaya mine.

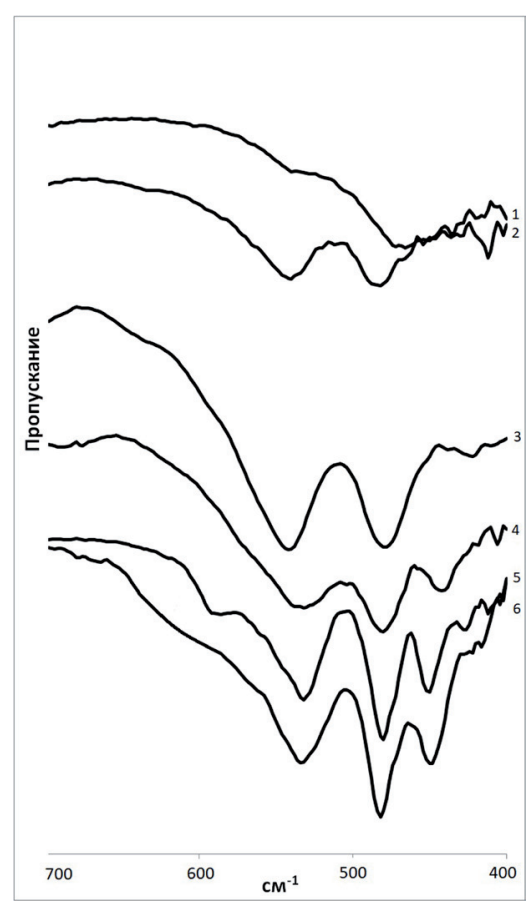

Таким образом, в копях Мокруша и Министерская нами установлены: Li-мусковит, трилитионит и полилитионит. В слюдах редкометальных пегматитов из копи Мокруша впервые описан Cs-трилитионит, пока не установленный в копи Министерская. Химический состав литийалюминиевых слюд из копи Министерская приводится впервые. Полученные данные микрозондового анализа и ИК-спектроскопии хорошо сопоставляются.

\section{Литература}

1. Канонеров А.А., Чудинова Н.Д. Мурзинские самоцветные копи (путеводитель и кадастр минералов) // Изд. 2-е: Уральская летняя минералогическая школа. Екатеринбург: Изд. УГГГА. 2000. С. 41

2. Павлишин В.И. Инфракрасные спектры слюд литиево-железистого изоморфного ряда // ЗВМО. 1975. Ч. 104. Вып. 1. С. 70-74.

3. Попов В.А., Попова В.И. Копь Мокруша: Очерк истории освоения и минералогия // Миасс: ИМинУрО PAH.1999. C. 71.

4. Ферштатер Г.Б., Бородина Н.С. Мурзинский массив на Среднем Урале как пример межформационного гранитного плутона: магматические источники, геохимическая зональность, особенности формирования // Литосфера. 2018 (5). С. 672-691.

5. Beran A. Infrared spectroscopy of micas // Reviews in Mineralogy \& Geochemistry, Miner. Soc. Amer. 2002. 46. P. 351-369.

6. Tischendorf G. et al. On Li-bearing micas: estimating Li from electron microprobe analyses and an improved diagram for graphical representation // Mineralogical Magazine. 1997. V. 61(6). P. 809-834. 